\title{
Uso de PRF para Reparo de Alvéolos Pós Exodontia de Terceiros Molares
}

\author{
Use of PRF for repair of alveole after exodontia of third molars \\ Uso de PRF para la reparación de alvetolos despúes de la exodoncia de terceros molares
}

Recebido: 26/10/2021 | Revisado: 04/11/2021 | Aceito: 05/11/2021 | Publicado: 09/11/2021

\author{
Isabella de Melo Veloso Benedito \\ ORCID: https://orcid.org/0000-0002-7529-4467 \\ Faculdade Patos de Minas, Brasil \\ E-mail: isa_veloso_@hotmail.com \\ Roberto Wagner Lopes Góes \\ ORCID: https://orcid.org/0000-0001-8183-6181 \\ Faculdade Patos de Minas, Brasil \\ E-mail: roberto.goes@faculdadepatosdeminas.edu.br \\ Lia Dietrich \\ ORCID: https://orcid.org/0000-0001-7887-8591 \\ Universidade Federal dos Vales do Jequitinhonha e Mucuri, Brasil \\ E-mail: lia.dietrich@ufvjm.edu.br \\ Marcelo Dias Moreira de Assis Costa \\ ORCID: https://orcid.org/0000-0001-9148-3674 \\ Universidade Federal de Uberlândia, Brasil \\ E-mail: marcelodmac@yahoo.com.br
}

\begin{abstract}
Resumo
A Fibrina Rica em Plaquetas (PRF) é um processo autólogo, que consiste na remoção de uma amostra de sangue retirada do paciente, onde a mesma é colocada em um tubo de ensaio, posteriormente sendo centrifugada, e depositada no alvéolo após a extração do terceiro molar. Esta terapia ainda está em avanços, porém que tem sido utilizado cada vez mais nas extrações de terceiros molares, onde auxilia na regeneração óssea e tecidual. O objetivo deste trabalho visa salientar a influência do PRF na regeneração tecidual e óssea, incluindo sua utilização e seus benefícios em alvéolos pós exodontia. A metodologia realizada constituiu em realizar uma revisão narrativa da literatura sendo pesquisadas obras em bases de dados científicos, como: Scielo, PubMed e LILACS no período de 1996 a 2020. Assim, a Fibrina Rica em Plaquetas atua como coadjuvante na cicatrização e regeneração óssea e tecidual, e por ser um processo autólogo os riscos de rejeição são mínimos. Conclui-se que, o PRF é um processo que ainda está em avanços, entretanto, é uma ótima alternativa para regeneração de alvéolos pós extrações de terceiros molares, por ter propriedades biológicas únicas.
\end{abstract}

Palavras-chave: Fibrina; Regeneração óssea; PRF.

\begin{abstract}
Fibrin Rica em Plaquetas (PRF) is an autologous process, which consists in the removal of a blood sample taken from the patient, where it is placed in a test tube, later centrifuged, and deposited in the alveole after extraction of the third molar. This therapy is still in advances, but it has been used more and more in the extractions of third molars, where it helps in bone and tissue regeneration. The objective of this work is to highlight the influence of PRF on tissue and bone regeneration, including its use and its benefits in alveolos after exodontia. The methodology was to perform a narrative review of the literature and researched works in scientific databases, such as: Scielo, PubMed and LILACS in the period from 1996 a 2020. Thus, Fibrina Rica em Plaquetas acts as an adjunct in bone and tissue healing and regeneration, and because it is an autologous process the risks of rejection are minimal. It is concluded that the PRF is a process that is still in progress, however, it is a great alternative for the regeneration of alveolos after extractions of third molars, because it has unique biological properties.
\end{abstract}

Keywords: Fibrina; Bone regeneration; PRF.

\section{Resumen}

La fibrina rica em plaquetas (PRF) es un proceso autólogo, que consiste en la extracción de una muestra de sangre tomada del paciente, donde se coloca en un tubo de ensayo, posteriormente se centrifuga, y se deposita en el alveol tras la extracción del tercer molar. Esta terapia aún está en avances, pero se ha utilizado cada vez más en las extracciones de terceros molares, donde ayuda en la regeneración ósea y tisular. El objetivo de este trabajo es destacar la influencia del PRF en la regeneración tisular y ósea, incluyendo su uso y sus beneficios en alveolos después de la exodontia. La metodología fue realizar una revisión narrativa de la literatura y trabajos investigados en bases de datos científicas, tales como: Scielo, PubMed y LILACS en el período de 1996 a 2020. Así, Fibrina Rica em Plaquetas actúa como un complemento en la cicatrización y regeneración ósea y tisular, y debido a que es un proceso autólogo los 
riesgos de rechazo son mínimos. Se concluye que el PRF es un proceso que aún está en curso, sin embargo, es una gran alternativa para la regeneración de alveolos después de extracciones de terceros molares, debido a que tiene propiedades biológicas únicas.

Palabras clave: Fibrina; Regeneración ósea; PRF.

\section{Introdução}

Os terceiros molares são os últimos dentes a erupcionarem na cavidade oral, com isso possuem uma maior chance de ausência de espaço na arcada dentária. Por esta razão são chamados também de dentes inclusos ou impactados. Esses dentes tornam-se impactados devido ao fato de o arco ósseo alveolar ser menor que o comprimento da arcada dentária (Vasconcellos, Oliveira, Melo-Luiz, Gonçalves, 2003).

Em sua maioria, os dentes impactados são quase sempre indicados para extração. No entanto, o pós-operatório desse tipo de extração, vem com um leque de preocupações e também de possíveis complicações, com isso o paciente tem o risco de infecções, dor, edema, osteíte alveolar, lesões nervosas a possíveis fraturas de mandíbula (Vasconcellos, Oliveira, Melo-Luiz, Gonçalves, 2003; Antunes, 2014)

Diante disso, a busca por formas de minimizar os efeitos negativos das extrações de terceiros molares, recomendou-se o uso de concentrados plaquetários só que de forma autóloga, ou seja, utiliza-se o sangue do próprio paciente, para auxiliar no processo de regeneração do local, seja em casos cirúrgicos ou em feridas (Cardoso, 2018).

Por ser um processo totalmente "natural", as Fibrinas Ricas em Plaquetas (PRF) possuem propriedades benéficas para a cicatrização tecidual e regeneração óssea. Pode-se dizer que o PRF tem um "poder" curativo, principalmente em regiões de tecido mole ao redor de incisões e de onde foi causada a ferida. São encontradas também citocinas plaquetárias, que são liberadas de acordo com que a fibrina é absorvida pelo organismo. Essas citocinas juntamente com os leucócitos, desempenham um papel de grande importância para evitar os processos infecciosos e inflamatórios (Cardoso, 2018).

O objetivo desse trabalho é mostrar a influência do PRF na regeneração tecidual e óssea, incluindo sua utilização e seus benefícios em alvéolos pós exodontia.

\section{Metodologia}

A presente pesquisa trata-se de uma pesquisa qualitativa, do tipo exploratória. O método de pesquisa empregado foi o método dedutivo. Para a formação da pesquisa apresentada foram utilizadas as duas fontes existentes, que são: a fonte primária e a fonte secundária.

Este estudo foi realizado por meio da revisão narrativa da literatura (Pereira et al., 2018). O trabalho foi realizado através da análise de artigos científicos, livros, monografias, revistas, dissertações e teses, sendo que o acesso a estes conteúdos serão possíveis através de livros presentes na biblioteca da Faculdade Patos de Minas e sites da busca, como o Google Acadêmico, SciELO, Lilacs, PubMed, entre outros. Foi utilizado para busca palavras-chaves como: Fibrina; Regeneração óssea; PRF e keywords: Fibrina; Bone regeneration; PRF.

\section{Revisão de literatura}

\subsection{Processo fisiológico do reparo alveolar pós exodontia}

Após a realização de uma exodontia, ocorre uma cascata de acontecimentos fisiológicos para reparo morfológico e funcional, tanto ósseo quanto tecidual. Imediatamente após a extração dentária, é formado um coágulo sanguíneo dentro do alvéolo, que gradativamente vai sendo invadido por fibroblastos que normalmente são originados da diferenciação de células mesenquimais ou pela mitose de outros fibroblastos já existentes, que se encontram no ligamento periodontal que está preso as 
paredes alveolares (Veronese, Milanezi, Okamoto, Okamoto. 2005; Montero-Sánchez, Cabrera-Peralta, Okamoto, 1996).

Posteriormente, ocorre a amplificação de tecido conjuntivo que é constituído principalmente por fibroblastos que darão origem as fibras colágenas. À medida que essas fibras colágenas se proliferam, há uma diminuição de células e de vasos sanguíneos, com isso dando início a fase de maturação do tecido conjuntivo (Veronese et.al, 2005).

$\mathrm{Na}$ parte inferior do alvéolo e das paredes alveolares se encontram os osteoblastos, que são responsáveis pela formação de matriz orgânica, através dessa matriz orgânica que são constituídas as trabéculas ósseas (Veronese et.al, 2005).

As trabéculas ósseas espessas e com canais medulares bem pronunciados, são encontradas dentro do alvéolo quando todo o processo de reparo ósseo e tecidual já está totalmente concluído (Veronese et.al, 2005).

Clark define o processo de cicatrização em três fases, que são divididas em: fase inflamatória, fase de proliferação ou de granulação e fase de maturação (Campos, Broges-Branco, Groth, 2007).

\subsection{Fase inflamatória}

Inicia-se após uma lesão, nesta fase acontece o transporte de tromboxana A2 e de prostaglandinas através das membranas celulares, que são vasoconstritoras. O processo de coagulação é excitado pelo endotélio lesionado e também pelas plaquetas que são responsáveis pelo processo de reparação tecidual. Em busca da homeostase, as plaquetas liberam grânulos, que são micropartículas, que possuem fatores de crescimento e que induzem os neutrófilos até a o local lesionado (Pimenta, Oliveira, Gomes, 2015).

Após 24 horas da lesão, os neutrófilos já estarão em um agrupamento maior ocupando quase totalmente a ferida, diante disso, eles irão concentrar-se nas paredes do endotélio através das ligações com receptores da membrana, produzindo radicais livres, que causam a lise bacteriana e aos poucos são trocados pelos macrófagos (Pimenta, Oliveira, Gomes, 2015; Junqueira, Carneiro, 2004).

Os macrófagos demoram em média de 48 a 96 horas até que se deslocam totalmente para a lesão, sendo responsáveis pela replicação celular e também pela remoção do tecido necrosado, processo pelo qual é iniciado através dos neurófilos. Outra função pertinente dos macrófagos, é secretar citocinas e os fatores de crescimento, que auxiliam na angiogênese, no processo de fibroplasia, que visa a produção de colágeno através dos fibroblastos, e pôr fim a produção de matriz extracelular, processos esses indispensáveis para a fase proliferativa (Pimenta, Oliveira, Gomes, 2015; Junqueira, Carneiro, 2004).

\subsection{Fase Proliferativa}

Nesse estágio, acontece um processo conhecido como fibroplasia, que é originado da multiplicação dos fibroblastos, sendo que o processo de fibroplasia ocorre através da atuação conjunta das citocinas. Posteriormente, as células endoteliais presentes nos fibroblastos se proliferam, formando uma volumosa rede de vascularização e também há uma formação volumosa de macrófagos, que darão origem aos tecidos de granulação (Pimenta, Oliveira, Gomes, 2015).

Nessa fase proliferativa, há uma subdivisão importante, são elas, neo-angiogênese, fibroplasia e epitelização (Pimenta, Oliveira, Gomes, 2015): Na neo-angiogênese, ocorre a proliferação de novos vasos sanguíneos (angiogenêse) para manter a hemostasia no processo de cicatrização da ferida. Basicamente, nesse processo acontece a nutrição dos tecidos do local da ferida, e o aumento da proliferação de células, como os macrófagos e fibroblastos (Pimenta, Oliveira, Gomes, 2015; Tazima, Vicente, Moriya, 2008).

No processo de fibroplasia, os fibroblastos são direcionados para a região inflamatória, se subdividem para produzir matriz extracelular. Os leucócitos fazem todo o trabalho de desinfecção, então somente depois de três dias da lesão que os fibroblastos irão se manifestar (Pimenta, Oliveira, Gomes, 2015; Tazima, Vicente, Moriya, 2008).

O colágeno é produzido através dos fibroblastos, que é uma de suas funções principais, que já começam na fase 
inflamatória da lesão. Esse colágeno é responsável pela estruturação e pela fortificação da cicatriz (Pimenta, Oliveira, Gomes, 2015; Tazima, Vicente, Moriya, 2008).

E por fim o processo de epitelização, nessa etapa após 24 a 36 horas da lesão, ocorre a proliferação de células epiteliais, através do crescimento epidérmico (Tazima, Vicente, Moriya, 2008).

Os queratinócitos são as principais células alvos dos traumas, são os que mais sofrem com qualquer tipo de alteração causada na pele. E também o responsável pela síntese de queratina. Após a migração dos queratinócitos da camada basal para a camada epitelial forma-se uma densa camada celular, que auxiliará na estruturação e fortificação do epitélio (Silva, Zambuzzi, 2013).

Os queratinócitos contidos na pele produzem a proliferação citocinas, que auxiliará na cicatrização das feridas da pele ou da região lesada (Pimenta, Oliveira, Gomes, 2015).

\subsection{Fase de maturação}

O processo de maturação começa na terceira semana após a lesão, e nisso ocorre a ampliação da força, porém sem adição de colágeno. As fibras de colágeno sofrerão apoptose através da colagenase. Essas modificações acarretam na restauração de uma nova matriz extracelular, processo esse responsável na cicatrização tecidual. A colagenase sintetizada através dos fibroblastos e por leucócitos faz com que haja a morte da matriz antiga. Após a estabilização entre renascimento e morte da matriz, ocorre então a conclusão desse processo de cicatrização (Pimenta, Oliveira, Gomes, 2015).

\subsection{A evolução dos concentrados plaquetários}

Os hemoderivados são produtos sintetizados em escala industrial, através da divisão do plasma por processos físicoquímicos (Razouk, Reiche, 2004). A utilização de hemoderivados começou no final dos anos 70 na Europa, usavam-se as colas de fibrinas, com a intenção de reparo das feridas, promovendo a hemostasia da lesão, mesmo havendo deficiência de coagulação (Giongo, 2017).

Independentes dos bons resultados das colas de fibrinas foram proibidas a sua comercialização em 1978 nos Estados Unidos, pelo fato de promover infeções cruzadas (Giongo, 2017).

Através da proibição da utilização de colas de fibrinas, começou-se a desenvolver novos tipos de hemoderivados, com base nos fatores de crescimento contidos nas plaquetas, com isso, dando vida aos concentrados plaquetários (Giongo, 2017).

\subsection{Plasma rico em plaquetas}

O plasma rico em plaquetas (PRP) é composto basicamente de plaquetas, fatores de crescimento, leucócitos, entre outras células contidas no plasma. O PRP tem como objeto principal o reparo tecidual (Giongo, 2017).

O PRP é obtido através da remoção de sangue do paciente, que é colocado em um frasco contendo citrato de sódio como anticoagulante. Esse coagulante é o mais recomendado devido as suas propriedades de ligação com íons de cálcio dando origem aos quelatos, que impede a coagulação precoce do plasma, em seguida, para obtenção do gel de plaquetas, coloca-se cloreto de cálcio, que o coágulo se formará de forma espontânea, posteriormente centrifugada (Aleixo, Coelho, Trajano, Andrade, 2018).

Para a produção de PRP, a centrifugação é essencial, a amostra pode ser centrifugada em uma etapa ou em duas. No processo de uma etapa, a amostra depois de centrifugada apresentará na parte do final do tudo as hemácias por ter maior peso, os leucócitos se localizam na parte central, e o plasma na parte superior. As plaquetas juntamente com os leucócitos, formam uma camada esbranquiçada, conhecida de zona névoa (Aleixo et al, 2018).

No processo feito em duas etapas, depois da centrifugação, as hemácias são retiradas e o plasma volta para a 
centrífuga, levando em consideração a queda das plaquetas e das poucas hemácias que possam estar presentes no tubo. Em seguida, $80 \%$ da parte superior do plasma, representa o plasma pobre em plaquetas (PPP), que é posteriormente descartado. Na parte inferior do tubo, encontra-se um botão plaquetário, que será recolocado com o plasma, dando origem ao PRP (Aleixo et $a l, 2018)$.

Além do reparo tecidual, o PRP tem auxiliado na hemostasia da lesão e também estimulando a angiogênese, com isso diminuindo as complicações pós-operatórias, potencializa o processo de cicatrização e diminui no tempo de recuperação do paciente (Aleixo et al, 2018).

\subsection{Fibrinas ricas em plaquetas}

As fibrinas ricas em plaquetas (PRF) são obtidas da mesma forma que o PRP, que é através do sangue do próprio paciente, porém sem uso de anticoagulantes ou de trombinas (Giongo, 2017).

Após a retirada de uma amostra de sangue, a mesma é colocada em um tubo de ensaio de $10 \mathrm{ml}$, onde é depositada em uma centrifuga que fará um movimento de rotação a $3000 \mathrm{rpm}$, por até 10 minutos, e sem qualquer adição de anticoagulantes. Logo após centrifugada a amostra, apresentará na forma de um coágulo, ou seja, aquele sangue que foi depositado no tubo, ficará dividido em três partes, sendo que na parte central do tubo terá um coágulo de fibrina, na parte inferior concentra-se os glóbulos vermelhos e na parte superior plasma acelular (Aleixo et al, 2018).

Para se obter essa fibrina de forma adequada para utilização, depende inteiramente do sucesso da técnica usada pelo profissional na retirada do sangue do paciente. É necessária que esta amostra seja coletada o mais rápido possível e imediatamente colocada na centrifuga (Aleixo et al, 2018).

Em casos de demora para esse processo, o sangue que está no tudo de ensaio em contato com o vidro, por ser um fator fisiológico do sangue, começará a coagular, e quando entrar em centrifugação produzirá menos coágulos sanguíneos, perdendo a consistência ideal para utilização, com isso inutilizando a amostra coletada (Hak, 2020).

Por ser um processo totalmente "natural", o PRF possui propriedades benéficas para a cicatrização tecidual e regeneração óssea (Hak, 2020). Pode-se dizer que o PRF tem um "poder" curativo, principalmente em regiões de tecido mole ao redor de incisões e de onde foi causada a ferida. São encontradas também citocinas plaquetárias, que são liberadas de acordo com que a fibrina é absorvida pelo organismo. Essas citocinas juntamente com os leucócitos, desempenham um papel de grande importância para evitar processos infecciosos e inflamatórios (Hak, 2020).

\subsection{Fibrinas ricas em plaquetas no reparo alveolar pós exodontias}

Com o uso do prf nos alvéolos pós extrações, o processo de cicatrização é acelerado pelo fato de que há uma liberação continua de fatores de crescimento (Hak, 2020). O prf reduz também os riscos de uma extração de terceiros molares, como o trismo, osteíte alveolar, edema, infecções (Giongo, 2017)

Outras formas de reparação tecidual e óssea com o uso do prf, é a combinação com enxertos alógenos, tem tido grande significância no ganho de volume ósseo, por conduzir a liberação de fibroblastos e de osteoblastos, promove a reepitelização da região lesada devido ao aceleramento da cicatrização (Hak, 2020).

\section{Discussão}

Dentre os concentrados plaquetários, o PRF mostra-se superior tanto para sua obtenção, que é feita de forma simples através do sangue do próprio paciente, o custo é relativamente baixo para ser preparado, e demonstra ser bastante eficaz. Outro ponto que deve ser considerado é o fato de que, para a preparação do PRF não é necessário o uso de coagulantes. Já o PRP, é necessário o uso de trombinas bovinas e cloreto de cálcio no processo de coagulação, o que de certo modo, o torna mais 
complexo. Por este acréscimo de coagulantes, a membrana começa o processo de coagulação de forma não homogênea podendo gerar resultados diferentes dependendo da forma de produção (Aleixo et al, 2018). Entende-se que o PRF em relação ao PRP, mostra-se mais eficaz devido as suas propriedades totalmente biológicas, levando também em consideração o custo para a obtenção de ambos, o PRF depende apenas do sangue do paciente, sem uso de aditivos. Em contrapartida, o PRP exige o uso de trombinas bovinas e cloreto de cálcio, que o faz ter um valor mais elevado, não sendo tão acessível aos pacientes como o PRF.

Após a realização de uma exodontia, ocorrem diversos processos fisiológicos para reparar o local lesionado. São formados coágulos sanguíneos, que posteriormente serão tomados por fibroblastos que darão origem as fibras colágenas. No interior do alvéolo e das paredes alveolares se encontram os osteoblastos, que são responsáveis pela formação de matriz orgânica, que são constituídas as trabéculas ósseas. As trabéculas ósseas espessas e com canais medulares bem pronunciados, são encontradas dentro do alvéolo quando todo o processo de reparo ósseo e tecidual já está totalmente concluído (Veronese et $a l$, 2005). Após ser inserido no local de ação, o PRF libera gradativamente fatores de crescimento, promovendo a proliferação de fibroblastos e osteoblastos, e também o processo de angiogênese, que consiste na formação de vasos sanguíneos originados de outros. Outro papel importante do PRF é a regulação da imunidade. As citocinas presentes no PRF são importantes na homeostase tecidual, sendo responsáveis por gerar o mecanismo de defesa (Hak, 2020). É fato que, para que ocorra o processo de cicatrização é necessário que haja uma cascata de fatores que levará a reparação óssea e tecidual. Com o uso do PRF, todo esse processo é acelerado devido a constante liberação de fatores de crescimento no local.

\section{Conclusão}

Conclui-se que, o uso do PRF em consultório odontológico é um processo relativamente novo, que está em processo de estudo, entretanto, a utilização das fibrinas em extrações de terceiros molares impactados, tem sido bastante promissor na recuperação do pós operatório dos pacientes submetidos a extrações mais complexas.

Diante dos diversos concentrados plaquetários, o que mais se assemelha ao processo de coagulação fisiológica é o PRF, por ser obtido através do sangue do próprio paciente, logo, possui menos chances de possíveis rejeições.

Outro ponto positivo do PRF se deve ao fato de acelerar o processo de reparação tecidual e a regeneração óssea. É importante que o cirurgião dentista esteja apto para executar o procedimento.

\section{Referências}

Aleixo, G. A. S., Coelho, M. CO. C., Trajano, S. C., \& Andrade, L. S. S. (2018) Plasma rico em plaquetas: mecanismo de ação, produção e indicações de uso - Revisão de literatura. UFRPE.

Antunes, H. D. A. (2014) Complicações associadas à extração de terceiros molares inclusos. Universidade Fernando Pessoa Faculdade Ciências Da Saúde.

Bittar, C. E. B. (2014) O direito na pós-modernidade. (3a ed.), Atlas.

Campos, A. C. L., Broges-Branco, A., \& Groth, A. K. (2007) Cicatrização de feridas. ABCD Arq Bras Cir Dig 2007; 20(1):51-8. UFP.

Cardoso, B. L. (2018) A utilização do l-prf no controle pós operatório após exodontia de terceiros molares. Unisul.

Cardoso, M. L., \& Lopes, S.M. (2015) Fibrina rica em plaquetas e leucócitos (l-prf). Diminuindo a morbidade em procedimentos de reconstruções teciduais orais. UFF.

Cunha, M. B. (2001) Para saber mais: fontes de informação em ciência e tecnologia. Brasília: Briquet de Lemos/Livros.

Faver, H. R. Z. (2018) Revisão comparativa entre agregados plaquetários e sangue total relacionados com osseointegração e titânio. UFSC,

GIL, A, C. (2002) Como elaborar projetos de pesquisa. (4a ed.), Atlas.

Giongo, T. S. (2017) Efeitos clínicos do l-prf após exodontia de terceiros molares: revisão de literatura. Unisul.

Hak, S. (2020) L-prf-Aplicação clínica em implantodontia. Unifacvest. 
Research, Society and Development, v. 10, n. 14, e459101422314, 2021

(CC BY 4.0) | ISSN 2525-3409 | DOI: http://dx.doi.org/10.33448/rsd-v10i14.22314

Hupp, Jame, R., Ellis, Edward, D. D. S., \& Tucker, Myro, R. (2009) Cirurgia oral e maxilofacial contemporânea. (5a ed.), Elsevier,xiv, 704 p. pp. $129-299$.

Lakatos, E. M, \& Marconi, M. A. (2003) Metodologia científica. (7a ed.), Atlas.

Junqueira, L. C., \& Carneiro, J. (2004) Histologia Básica. Guanabara Koogan. 488.

Montero-Sánchez, I., Cabrera-Peralta, C., \& Okamoto, T. (1996) Influência da desnervação regional no processo de reparo alveolar. Estudo histológico em ratos. Rev. Odontol. UNESP, 25(2): 327-344.

Pereira, A., Shitsuka, D. M., Parreira, F. J., \& Shitsuka, R. (2018). Metodologia da Pesquisa Científica. UFSM. https://repositorio.ufsm.br/bitstream/hand le/1/15824/Lic_Computacao_Metodologia-Pesquisa-Cientifica.pdf?sequence=1

Pimenta, I. P., Oliveira, N. M. M., \& Gomes, A. C. P. (2015) Processo de reparo tecidual do alvéolo dental - Uso da Boneheal para regeneração óssea guiada (rog). UNIFRAN.

Razouk, F. H., \& Reiche, E. M. V. (2004) Caracterização, produção e indicação clínica dos principais hemocomponentes. Rev Bras Hematologia e Hemoterapia. 26(2).

Rodrigues. G. (2015). Fibrinas ricas em plaquetas, uma alternativa para regeneração tecidual: revisão de literatura. J Oral Invest, 4(2): 57-62

Silva, R. A., \& Zambuzzi, F. W. (2013) Queratinócitos e seus desafios: uma revisão da literatura sobre mecanismos intracelulares. Saúde VER. 13(35), 3-14.

Tazima, M. F. G. S., Vicente, Y. A. M. V. A, \& Moriya, T. (2008) Biologia da ferida e cicatrização. Medicina. 41(3): 259-64.

Vasconcellos, R. J. H., Oliveira, D. M, Melo-Luiz, A. C., \& Gonçalves, R. B. (2003) Ocorrência de dentes impactados. Rev Cir Traumatol Buco-Maxilo-Fac.

Veronese, R. M, Milanezi, L. A, Okamoto, R., \& Okamoto T. (2005) Processo de reparo em feridas de extração dental. Interferência da solução anestésica contendo articaína 4\% + adrenalina 1:100.000: análise histológica em ratos. Rev. Odontol. de Araçatuba, 26(1), 65-72. 